\title{
INFLUENCES OF SODIUM PARA-AMINO SALICYLATE, PYRAZINAMIDE, AND ISONICOTINIC ACID HYDRAZIDE UPON THE GROWTH OF TIMOTHY
}

\author{
YUTAKA SATO \\ Shonan Hygiene Institute, Kamakura, Japan
}

(Received for publication October 5, 1960)

The seeds of timothy (Phleum pratense), when they were planted on the cotton moistened with solution of antibiotics such as streptomycin, kanamycin, or viomycin, produced colorless leaves lacking in chlorophyll(1). In the case of streptomycin the disturbance of chlorophyll formation occurs when the seeds are exposed to streptomycin not only at their germinating stage but also in their resting condition, that is, the seeds treated with streptomycin at a lower temperature in a refrigerator for a few days develop only colorless leaves when they are germinated, after being separated from streptomycin, on the cotton moistened with pure water(2). According to Euler(3), penicillin, sulfanil amide, guanidin etc. do not hinder the chlorophyll formation in certain green plants. In the previous paper(1), the author reported preliminarily that antituberculous chemotherapeutic agents such as sodium para-amino salicylate, pyrazinamide, and isonicotinic acid hydrazide had no hindering effect on the chlorophyll formation in the timothy, though, depending on their concentration, the growth of timothy could be disturbed.

It was further demonstrated that these three drugs differed from streptomycin not only in their effect on chlorophyll formation but also in another mode of action on the seeds, as reported in this paper.

\section{MATERIALS AND METHODS}

Sodium para-amino salicylate (PAS), pyrazinamide (PZA), and isonicotinic acid hydrazide (INAH) used in this experiment were all commercial products for clinical use.

The culture medium was pharmacopoeia absorbent cotton moistened with pure water or drug solution. For this purpose about $1.5 \mathrm{~g}$ of cotton was stuffed in each glass plate which was $5 \mathrm{~cm}$ in diameter and $1.5 \mathrm{~cm}$ in depth.

The seeds of timothy were put into contact with these antituberculous agents in following two ways :

1. The seeds were planted on the cotton moistened with the above drug 
solutions at various concentrations and cultivated at $24^{\circ} \mathrm{C}$.

2. The seeds were soaked in the drug solutions at various concentrations for 4 days at $5^{\circ} \mathrm{C}$, and then planted, after being separated from these solutions, on the cotton moistened with pure water and cultivated at $24^{\circ} \mathrm{C}$.

The measurement of timothy growth were made on the 10th culture day.

\section{EXPERIMENTAL RESULTS}

1. Growth of timothy developed on the cotton moistened with solution of antituberculous drug

The timothy seeds were germinated on the cotton moistened with various concentrations of PAS, PZA, or INAH. As shown in table 1, when the concentrations were $10 \mathrm{mg} / \mathrm{cc}$ for $\mathrm{PAS}, 900 \mathrm{r} / \mathrm{cc}$ for $\mathrm{PZA}, 500 \mathrm{r} / \mathrm{cc}$ for INAH, the timothy growth (germinating ability and growth of leaf blades) was disturbed remarkably, though the chlorophyll formation appeared undisturbed. This is one of the differences seen in the effect between streptomycin and the drugs mentioned above.

Table 1

Growth of Timothy Developed on the Cotton Moistened with Solutions of Antituberculous Drugs

\begin{tabular}{|c|c|c|c|}
\hline \multirow{2}{*}{$\begin{array}{l}\text { Kind of drugs and } \\
\text { their concentration } \\
\text { in the culture solu- } \\
\text { tion }\end{array}$} & \multicolumn{3}{|c|}{$\begin{array}{l}\text { Growth of timothy developed on the cotton moistened } \\
\text { with drug solutions }\end{array}$} \\
\hline & $\begin{array}{c}\text { Rate of } \\
\text { germination } \\
\%\end{array}$ & $\begin{array}{l}\text { Length of } \\
\text { leaves } \\
\text { cm }\end{array}$ & $\begin{array}{l}\text { Chlorophyll } \\
\text { formation }\end{array}$ \\
\hline \multicolumn{4}{|l|}{ Sodium para-amino salicylate } \\
\hline $1 \mathrm{mg} / \mathrm{cc}$ & 100 & 3.6 & normal \\
\hline $5 \mathrm{mg} / \mathrm{cc}$ & 95 & 2.9 & " \\
\hline $10 \mathrm{mg} / \mathrm{cc}$ & 22 & 1.1 & " \\
\hline \multicolumn{4}{|l|}{ Pyrazinamide } \\
\hline $100 \gamma / \mathrm{cc}$ & 98 & 3.5 & normal \\
\hline $450 \gamma / \mathrm{cc}$ & 42 & 2.2 & $"$ \\
\hline $900 \gamma / c c$ & 21 & 1.5 & " \\
\hline \multicolumn{4}{|l|}{ Isonicotinic acid hydrazide } \\
\hline 100 ricc & 97 & 2.2 & normal \\
\hline $300 \gamma / \mathrm{cc}$ & 92 & 1.5 & $"$ \\
\hline $500 \gamma / \mathrm{cc}$ & 8 & 0.8 & almost normal \\
\hline \multicolumn{4}{|l|}{ Streptomycin } \\
\hline $200 \gamma / \mathrm{cc}$ & 98 & 1.8 & no formation \\
\hline $\begin{array}{l}\text { Water purified by passing through } \\
\text { ion exchange resin }\end{array}$ & 98 & 3.6 & normal \\
\hline
\end{tabular}


2. Growth of timothy developed from the seeds which had previously been soaked in the drug solutions under a resting condition

The seeds were soaked in the drug solutions for 4 days at $5^{\circ} \mathrm{C}$. The concentrations of the drugs were made as follows in three gradations :

(1) Concentrations at which the germinating ability and the growth of leaves were markedly disturbed when the seeds were planted directly on the drug containing cotton, that is, $10 \mathrm{mg} / \mathrm{cc}$ for PAS, $900 \mathrm{r} / \mathrm{cc}$ for PZA, and $500 \mathrm{r} / \mathrm{cc}$ for INAH.

(2) Concentrations five times higher than (1), namely $50 \mathrm{mg} / \mathrm{cc}$ for PAS, 4.5 $\mathrm{mg} / \mathrm{cc}$ for PZA, and $2.5 \mathrm{mg} / \mathrm{cc}$ for INAH.

(3) Concentrations ten times higher than (1), namely $100 \mathrm{mg} / \mathrm{cc}$ for PAS, $9 \mathrm{mg} /$ cc for PZA, and $5 \mathrm{mg} / \mathrm{cc}$ for INAH.

After the seeds were soaked in each drug solution of above concentration, they were planted on the cotton moistened with pure water after being sepa-

Table 2

Growth of Timothy Developed from the Seeds which had previously been Soaked in Drug Solution at $5^{\circ} \mathrm{C}$ for 4 Days before Cultivation

\begin{tabular}{|c|c|c|c|}
\hline \multirow{2}{*}{$\begin{array}{l}\text { Kind of drug solutions, } \\
\text { in which the seeds were } \\
\text { previously soaked before } \\
\text { cultivation }\end{array}$} & \multicolumn{3}{|c|}{$\begin{array}{l}\text { Growth of timothy developed on the cotton moistened } \\
\text { with pure water }\end{array}$} \\
\hline & $\begin{array}{c}\text { Rate of } \\
\text { germination } \\
\%\end{array}$ & $\begin{array}{l}\text { Length of } \\
\text { leaves } \\
\mathrm{cm}\end{array}$ & $\begin{array}{l}\text { Chlorophyll } \\
\text { formation }\end{array}$ \\
\hline \multicolumn{4}{|l|}{ Sodium para-amino salicylate } \\
\hline $10 \mathrm{mg} / \mathrm{cc}$ & 98 & 3.7 & normal \\
\hline $50 \mathrm{mg} / \mathrm{cc}$ & 97 & 3.8 & $"$ \\
\hline $100 \mathrm{mg} / \mathrm{cc}$ & 98 & 3.8 & $"$ \\
\hline \multicolumn{4}{|l|}{ Pyrazinamide } \\
\hline $900 \gamma / \mathrm{cc}$ & 96 & 3.8 & normal \\
\hline $4.5 \mathrm{mg} / \mathrm{cc}$ & 98 & 3.6 & $"$ \\
\hline $9 \mathrm{mg} / \mathrm{cc}$ & 96 & 3.8 & " \\
\hline \multicolumn{4}{|l|}{ Isonicotinic acid hydrazide } \\
\hline $500 \gamma / \mathrm{cc}$ & 96 & 3.7 & normal \\
\hline $2.5 \mathrm{mg} / \mathrm{cc}$ & 97 & 3.8 & $"$ \\
\hline $5 \mathrm{mg} / \mathrm{cc}$ & 99 & 3.8 & "l \\
\hline \multicolumn{4}{|l|}{ Streptomycin } \\
\hline $200 \gamma / \mathrm{cc}$ & 96 & 2.2 & no formation \\
\hline $\begin{array}{l}\text { Water purified by passing through } \\
\text { ion exchange resin }\end{array}$ & 96 & 3.8 & normal \\
\hline
\end{tabular}

Note: (1) The seeds which were soaked in drug solutions at $5^{\circ} \mathrm{C}$ for 4 days were planted, after being separated from drugs, on the cotton moistened with pure water and cultivated at $24^{\circ} \mathrm{C}$. The growth of timothy was measured on the 10 th culture day. (2) These data were obtained with the seed-batch of 1960 and experiments were made during May and June. 
rated from the drug. As shown in table 2, no toxic effect of the drugs appeared in the timothy growth. This is another difference seen between streptomycin and these drugs.

\section{DISCUSSION}

Although PAS, PZA, and INAH have antituberculous activity like streptomycin, they are different from the latter in the influence on the timothy growth on the following two points: (1) Unlike streptomycin, these drugs could not disturb chlorophyll formation. (2) The seeds which had previously been treated with these drugs under a resting condition could produce apparently normal leaves. In the leaves any toxic effect failed to be found which was observed when the seeds were planted on the drug containing cotton. In the case of streptomycin, the exposure of the seeds to streptomycin at $200 \mathrm{r} / \mathrm{cc}$ resulted in the chlorophyll disturbance. This occurred even when the seeds were soaked in the solution of streptomycin under a resting condition before the germination $^{(2)}$. Of course, the disturbance was manifest when the seeds were planted directly on the cotton moistened with solution of streptomycin(1).

\section{SUMMARY}

1. When the timothy seeds were planted on the cotton moistened with the solution of sodium para-amino salicylate $(10 \mathrm{mg} / \mathrm{cc})$, pyrazinamide $(900 / \mathrm{cc})$, or isonicotinic acid hydrazide $(500 \mathrm{r} / \mathrm{cc})$, their germinating ability and leaf growth would be disturbed remarkably, but the chlorophyll formation was not disturbed.

2. Even when the seeds were soaked in the solution of sodium para-amino salicylate $(100 \mathrm{mg} / \mathrm{cc})$, pyrazinamide $(9 \mathrm{mg} / \mathrm{cc})$, or isonicotinic acid hydrazide $(5 \mathrm{mg} / \mathrm{cc})$ for 4 days at $5^{\circ} \mathrm{C}$, no toxic effect appeared in their germinating ability and leaf growth, when they were growing on the cotton moistened with pure water after being separated from the drugs.

The author is indebted to Dr. Hideo Moriyama, the director of this institute, for his many valuable advices and encouragements.

\section{REFERENCES}

1. Sato, Y.: Effect of streptomycin on the chlorophyll formation in the timothy. I. Morphological observation. Keio J. Med., 8: 187-198, 1959.

2. Sato, Y.: Effect of streptomycin on the chlorophyll formation in the timothy. II. Influences of inorganic salts upon the streptomycin effect on the timothy seeds (under a resting condition). Keio J. Med., 9: 25-32, 1960.

3. Euler, H. von: Ueber die Keimung von Samen unter Einwirkung Antibiotischer Stoffe. Ark. Kemi Menerol. Geol., 25 A (17) : 1-9. 1947. 